\title{
Sobre o método crítico de Antonio Candido em Formação da Literatura Brasileira
}

\author{
Marcos Rogério Cordeiro Fernandes \\ Universidade Federal de Minas Gerais
}

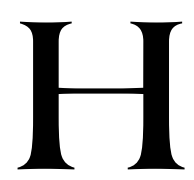

á quase 50 anos foi publicado o mais importante livro sobre a literatura no Brasil: Formação da literatura brasileira: momentos decisivos (1959) de Antonio Candido. Acredito que nunca é demais comentar alguma coisa sobre o livro, oportunidade para repensar algo de sua contribuição para a crítica literária praticada hoje no país e no mundo. Não há exagero nessa afirmativa, pois, desde sua primeira edição, Formação foi lida por gerações seguidas de professores, alunos e pesquisadores na área de Letras - como era de se esperar - e de qualquer outra que tratasse de questões históricas e culturais. Em suma, comentar, mesmo que brevemente, uma obra como essa é uma oportunidade para frisar alguns de seus aspectos (a importante contribuição para os estudos literários; a relação com outras obras de crítica, história e sociologia; a conduta de análise de uma obra literária; a perspectiva teórica sofisticada usada com moderação; a articulação inteligente entre visão ampla de movimento e atenção focada no detalhe etc.), relacioná-los e verificar sua atualidade.

Formação fora prometida por Antonio Candido ao editor para ser concluída em dois anos e ser um livro de história da literatura brasileira, mas levou doze anos de preparação (1945-1957) e se limitou a tratar basicamente de dois movimentos literários (Arcadismo e Romantismo). Durante esse tempo, Antonio Candido, que já era livre-docente em literatura com uma tese sobre a crítica histórico-sociológica praticada no Brasil no final do século 19 e início do 20 ( O método crítico de Sílvio Romero), preparava também sua tese de doutoramento em Sociologia (Os parceiros do Rio Bonito: estudos sobre o caipira paulista e a transformação dos seus meios de vida), cadeira que ocupava na Universidade de São 
Paulo e a qual abandonou logo em seguida para se dedicar exclusivamente ao estudo da literatura, vindo a introduzir no início da década de 1960 a cadeira de Literatura Comparada na Unesp de Assis. Mesmo quem faz uma leitura ligeira da obra de Antonio Candido percebe que sua formação como sociólogo está longe de ser considerada secundária em sua atividade como crítico. Numa leitura mais atenta, pode-se mesmo ver que devemos justamente a essa formação a base da complexidade e profundidade de suas análises. Frisando bem a idéia: é na complementaridade (densa e bem pensada) entre visão histórico-sociológica e perspicácia crítica voltada para o texto que reside a inspiração definitiva que organiza todo o padrão da argumentação desenvolvida em Formação. Entretanto, essa característica esconde uma pequena armadilha: embora tal complementaridade seja fácil de reconhecer, ela possui, no entanto, um alcance nada evidente. Tal alcance é o grande responsável pela novidade ainda atual do livro e, por assim dizer, seu adiantamento. Trazendo o debate para o tema que aqui interessa, digamos que o eixo central da obra reside em seu método, desdobrado em três aspectos distintos, porém combinados: a organização disciplinada do material recolhido, a concepção de história que organiza e dá unidade ao livro por inteiro e a articulação entre literatura e relações culturais.

O primeiro ponto a se tratar - a escolha e a organização do material - talvez seja o mais polêmico: para os que questionam o enfoque do livro, Antonio Candido haveria priorizado a importância de apenas dois movimentos literários em detrimento dos demais e, assim, construído uma argumentação esteticamente questionável e historicamente limitada. Sem esquecer que não foram poucos os que criticaram esse aspecto, lembremos aqueles que foram mais incisivos e que desenvolveram idéias mais sistemáticas acusando a falha em Formação: a exclusão deliberada do Barroco do processo de constituição histórica da literatura no Brasil. Afrânio Coutinho, por exemplo, parte do pressuposto de que Antonio Candido não compreendeu a literatura barroca, o que desqualificaria sua argumentação; além disso, para ele, haveria uma distorção de caráter histórico, pois a verdadeira "formação" da literatura no Brasil já havia se dado no Barroco; o Arcadismo e o Romantismo corresponderiam a uma outra fase, quando a autonomia já havia sido conquistada. ${ }^{1}$ Para Haroldo

\footnotetext{
${ }^{1}$ COUTINHO, 1960, p. 59 e 64.
} 
de Campos trata-se de um verdadeiro "seqüestro" da fase mais importante e substanciosa da história de nossa literatura, resultando na negação de sua modernidade prematura (o barroco influenciaria no modernismo e no concretismo) e de sua universalidade (a obra de Gregório de Matos possuiria a mesma importância literária da de outros poetas quinhentistas e seiscentistas). ${ }^{2}$

As objeções de Afrânio Coutinho e Haroldo de Campos à tese de Antonio Candido já foram analisadas e conseqüentemente refutadas com equilíbrio e inteligência ${ }^{3}$ e não cabe aqui relembrá-las ponto por ponto, mas tão somente encaminhar suas implicações no terreno restrito dos interesses desse artigo. Para começar, podemos inferir que o interesse de Antonio Candido em Formação nunca foi retomar a história da literatura brasileira como um todo - embora esse fosse o projeto inicial de 1945 . Ao contrário, o crítico estava interessado em reconstruir seus "momentos decisivos", como indica o subtítulo da obra. O objetivo não é simples de compreender, embora venha explicado sem muita ênfase na "Introdução": segundo o autor, "o livro procura estudar a formação da literatura brasileira como síntese de tendências universalistas e particularistas". ${ }^{4} \mathrm{O}$ leitor familiarizado com os textos críticos de Antonio Candido reconhecerá aí a base de sua metodologia dialética, que procura encontrar a movimentação de forças contrárias nos fatos, nas idéias e nas formas. Isso ocorre nos trabalhos sobre história da literatura (Formação e Iniciação à literatura brasileira), nos de crítica cerrada do texto (Na sala de aula, "De cortiço a cortiço", "Dialética da malandragem"), nos estudos sobre sociologia e sociólogos (Parceiros do Rio Bonito, "Euclides da Cunha sociólogo"), nos de crítica cultural ("Literatura de dois gumes", "Literatura e subdesenvolvimento", "Literatura e cultura de 1900 a 1945"), nos de teoria ("Crítica e sociologia", "Literatura e vida social") etc.

Em Formação o esquema funciona mais ou menos assim: em lugar de apresentar a história da literatura de maneira tradicional (descrevendo

${ }^{2}$ CAMPOS, 1989, p. 46-59.

${ }^{3}$ Sobre o contraste entre as visões de Antonio Candido e Afrânio Coutinho, ver o estudo de Guilherme Simões Gomes Junior; sobre Antonio Candido e Haroldo de Campos, ver Gonzalo Aguilar e Leda Tenório Motta. Indicação completa consta no final na bibliografia.

${ }^{4}$ CANDIDO, 1981, p. 23. 
e comparando os movimentos, antepondo idéias estéticas e resultados artísticos distintos, buscando em uma escola a negação e superação das conquistas e limites da anterior - atitudes que no terreno da metodologia historiográfica costumamos chamar de dualistas, isto é, baseadas na anteposição excludente de duas linhas de forças que se negam mutuamente), Antonio Candido procurou, primeiro, especificar a complexidade dos movimentos e, a seguir, articulá-los de forma a configurar uma unidade orgânica e contraditória ao mesmo tempo: "é preciso ver simples onde é complexo, tentando demonstrar que o contraditório é harmônico". 5 Desse modo, o Arcadismo, que representa a verve universalista e conseqüentemente deslocada com suas imagens de pastores zanzando entre penhascos agrestes imaginando passear nos bosques ou à beira de remansos, também representa - ao mesmo tempo e ao contrário - um processo de aclimatação no qual se entroniza e se altera a experiência estética como produto e como produtora da experiência social. Quer dizer, ao desajustamento das imagens pastoris - tão exploradas no arcadismo - corresponde uma sensação espiritual mais ampla, um resíduo cultural que fazia com que os homens de pensamento se sentissem desterrados em sua própria terra, porque tudo o que era vivido na experiência contradizia o que era vivido no sentimento. ${ }^{6}$ Por sua vez, o Romantismo, ao qual não se pode negar o tom localista gritante na pintura da paisagem, na elevação simbólica do índio, na reformulação da linguagem em busca de colorido nacional, atravessa seus próprios limites ao criar um tipo de caracterização cheia de clichês dessa mesma paisagem, desse mesmo índio e dessa mesma linguagem. Assim, na luta para penetrar mais fundo em nossas tradições, o Romantismo acabou criando um paradoxo como resultado do deslocamento cultural: descrevendo nossa realidade a partir de imagens já estilizadas, que se referiam a um código simbólico já estabelecido e que nossos escritores aprenderam e muitas vezes reproduzia de forma disparatada. ${ }^{7}$ Em síntese, Antonio Candido procurou, através de análise

${ }^{5}$ CANDIDO, 1981, p. 31.

${ }^{6}$ A respeito ver HOLANDA, 1991. P. 227-231 e 257-261; LOPES, 1997. p. 87100; SERNA, 1995, p. 40-46.

7 A respeito ver BOSI, 1992, p.176-193; PINTO, 1995, p. 159-200; BAREL, 2002, p. 107-146. 
literária, interpretar a constituição (em sentido forte) de uma linha de força na literatura praticada no Brasil que vinha se projetando antes da Independência e que não chegou a ser concluída depois. Arcadismo e Romantismo representam "momentos decisivos" no processo de formação da literatura no Brasil na medida em que oferecem respostas variadas ao dilema de se construir um universo espiritual e estético autônomo e, ao mesmo tempo, integrado ao mundo cultural do ocidente. Neste particular, Antonio Candido está bem longe da tese americanista e despido de qualquer brasileirismo proselitista que se pode encontrar em A tradição afortunada, ${ }^{8}$ por exemplo, e bem próximo do ideal machadiano segundo o qual a literatura nacional deve integrar temas e problemas universais aos assuntos locais. ${ }^{9}$ Supera-se assim uma atitude tipicamente historicista (tão comum nos estudos literários) que procura na sucessão cronológica a explicação para as transformações na vida mental, como se a evolução linear e progressiva do tempo histórico desenhasse um horizonte cultural no qual obras e autores se ligariam num processo de acumulação contínua de consciência pátria e talento artístico. Ao contrário, o que se encontra em Formação é a confrontação no detalhe e em seu movimento de características específicas que atendem de maneira variada à demanda cultural do país, acentuando (e não encobrindo) as contradições desse processo.

Em um livro de crítica, mas escrito do ponto de vista histórico, como este, as obras não podem aparecer em si, na autonomia que manifestam; aparecem, por força da perspectiva escolhida, integrando em dado momento um sistema articulado e, ao influir sobre a elaboração de outras, formando, no tempo, uma tradição. ${ }^{10}$

Quer dizer, não se intentou a interpretação de obras na linha do tempo, sucedendo-se umas às outras, como individualidades mais ou menos autônomas, mas o domínio de um acervo subordinado a um método de análise. Tudo isso nos leva ao segundo aspecto da metodologia do livro - a concepção de história que o organiza como um todo. Para melhor compreender esse ponto, faz-se importante lembrar um pequeno ensaio escrito por Antonio Candido que serviu de prefácio ao clássico de Sérgio

${ }^{8}$ COUTINHO, 1968, p. 159-189.

${ }^{9}$ ASSIS, 1994, p. 803.

${ }^{10}$ CANDIDO, 1981, p. 24. 
Buarque de Holanda, Raizes do Brasil. ${ }^{11}$ Nele o crítico faz um pequeno inventário dos livros que marcaram sua geração e criaram a necessidade e a expectativa de uma visão desobstruída sobre o país. Os livros são, além de Raizes (1936), Casa grande E senzala (1933) de Gilberto Freyre e Formação do Brasil contemporâneo (1942) de Caio Prado Jr.. Antonio Candido chama atenção para o adensamento crítico de um livro para o outro, a perspectiva analítica inovadora que vai se descortinando e o anticonvencionalismo intelectual que a partir de então virara uma tradição no Brasil, reconfigurando os estudos históricos, sociais, econômicos e culturais. À lista de Candido podemos acrescentar outros livros que vinham justamente para dar continuidade a essa perspectiva crítica: Cultura brasileira (1943) de Fernando Azevedo, Os donos do poder (1958) de Raimundo Faoro e Formação econômica do Brasil (1959) de Celso Furtado, publicado no mesmo ano de Formação da literatura brasileira. Em todos esses livros podemos encontrar de maneira explícita ou não a concepção de que a história social brasileira foi construída a partir de uma dialética tensa e cheia de implicações entre forças de impulso contrárias: uma que se exercia de fora do país para dentro e outra que se desenvolvia internamente, não como projeção da primeira, nem como oposição a ela, mas com relação a ela. Assim, de uma maneira própria e com preocupações e temas específicos, todos esses livros se esforçaram para compreender e explicar o Brasil como uma sociedade marcada por certas especificidades, mas articulada a outras sociedades que determinavam - de maneiras variadas e em variados setores - o ritmo e a direção de nossa projeção histórica. Perpassa por todos eles a idéia de que para chegar a ser considerada uma formação social em sentido pleno, no correr de sua história a sociedade brasileira foi se armando a partir da paulatina articulação entre diversas estruturas que a compõem (economia, ideologia, política, cultura). Seguindo esse fio de raciocínio, somente quando todas as estruturas alcançassem um padrão de amadurecimento ao ponto de se articularem dentro de um sistema contínuo de funcionamento, o Brasil poderia ser considerado como uma Nação. Trata-se de um processo de "formação" lento e difícil, cheio de marchas e contra-marchas, marcado por contradições diversas e que produz efeitos em cada uma de suas estruturas: economia, ideologia,

\footnotetext{
${ }^{11}$ CANDIDO, 1981, p. XI.
} 
política e cultura. Assim, o problema da "formação", conceito que aparece no título ou no subtítulo da maioria dos livros citados acima, aparece como uma varinha de condão que cria a possibilidade de construção de uma teoria crítica sobre o Brasil.

Isso ajuda a compreender melhor o que foi analisado anteriormente e leva mais longe e fundo suas conseqüencias: quando Antonio Candido parte de dois movimentos literários escolhidos (Arcadismo e Romantismo) e os articula como momentos decisivos do processo de formação da literatura brasileira, ele submete essa escolha a uma concepção estruturadora da história cultural. Essa concepção não é propriamente histórica, como afirma Afrânio Coutinho, ${ }^{12}$ nem substancialista ou ideológica ou ainda evolutiva-linear-integrativa, como diz Haroldo de Campos, ${ }^{13}$ nem descritiva como quer Luiz Costa Lima. ${ }^{14}$ Sua concepção é dialética: ele parte da premissa de que elementos diversos e com força própria (autor, obra e público) se encontram em relação numa determinada conjuntura histórica e cultural de modo que criam um sistema integrado que possibilita a sua retroalimentação contínua e transformadora. Embora esses elementos já existissem no período do Barroco, eles não haviam ainda criado as condições de sua autoreprodução transformadora das relações necessárias para que se constitua um "sistema".

Se desejarmos focalizar os momentos em que se discerne a formação de um sistema, é preferível nos limitarmos aos seus artífices imediatos, mais os que vão enquadrando como herdeiros nas suas diretrizes, ou simplesmente no seu exemplo. Trata-se, então, para dar realce às linhas, de averiguar quando e como se definiu uma continuidade ininterrupta de obras e autores cientes quase sempre de integrarem um processo de formação literária. Salvo melhor juízo, sempre possível em tais casos, isto ocorre a partir dos meados do século XVIII, adquirindo plena nitidez na primeira metade do século XIX [quando] surgem homens de letras formando conjuntos orgânicos e manifestando em graus variáveis a vontade de fazer literatura brasileira. Tais homens foram considerados fundadores pelos que os sucederam,

\footnotetext{
${ }^{12}$ COUTINHO, 1960. p. 55.

${ }^{13}$ CAMPOS, 1989. p. 12, 16 e 36.

${ }^{14}$ LIMA, 1991. p. 159 e 165.
} 
estabelecendo-se deste modo uma tradição contínua de estilos, temas, formas ou preocupações. ${ }^{15}$

Neste ponto, a tese de Antonio Candido se aproxima muito da de outro dialético brasileiro, Caio Prado Jr., que em Formação do Brasil contemporâneo (atente-se para o título do livro e lembre-se do inventário do próprio Candido) buscava analisar as premissas históricas que possibilitaram a passagem do Brasil da condição de Colônia para a de Nação. Segundo Caio Prado, a Colônia possuía todos os elementos essenciais à Nação, mas não se constituía como tal, não porque não havia atividades internas, mas porque tais atividades estavam orientadas para atender objetivos externos. A constituição histórica da Nação exige, pois, o funcionamento de todos os setores internos integrados perfazendo um sistema orgânico e contínuo. ${ }^{16}$ Do ponto de vista metodológico também é possível identificar uma aproximação entre os dois livros: tal como Candido, Caio Prado parte de uma concepção estruturadora do objeto a ser analisado, configurando a construção de um problema e não a descrição de um processo. ${ }^{17}$

Se a comparação estiver correta, a tese que Antonio Candido desenvolve está baseada no pressuposto de que o sistema literário é algo constitutivo de um sistema anterior: o processo histórico-social. O termo de comparação e aferição - que permite ir da literatura à história e voltar - reside no conceito operatório de forma, ao qual o crítico empresta uma conotação filosófica determinada, como se verá adiante.

Sistematizando, ao desenvolver uma concepção de história para tratar da literatura brasileira, Antonio Candido põe duas questões de ordem. Em primeiro lugar, ele desdobra temas e problemas que se desenvolveram no âmbito da história e da sociologia para o âmbito estético, procurando encontrar no dinamismo específico desse último, o

${ }^{15}$ CANDIDO, 1981. p. 24-25.

${ }^{16}$ PRADO Jr., 1989, p. 31-32.

17 "Os pormenores e incidentes mais ou menos complexos que constituem a trama da história e que ameaçam por vezes nublar o que verdadeiramente forma a linha mestra que a define, passam para o segundo plano. E se escolhi um dela, apenas a última página, foi tão-somente porque aquele momento se apresenta como um termo final e a resultante de toda nossa evolução anterior. A sua síntese.” PRADO Jr., 1989, p. 20. 
nexo estruturador do pensamento que dá forma à arte literária em estágio de "formação". E faz isso sem reduzir categorias e esquemas de análise próprios dos estudos literários a outro tipo, ou seja, ele assegura a validade histórica de uma obra literária a partir de sua propriedade estética. Em segundo lugar, ele encaminha e desenlaça um problema de origem histórico-cultural que aqueles que fizeram história literária antes dele (José Veríssimo, Sílvio Romero e Araripe Júnior, por exemplo) já haviam identificado, formando, assim, uma espécie de tradição na crítica literária que via na literatura matéria para pensar e debater o destino do país. Mas é importante lembrar que nenhum deles viu chances de solução para o dilema, basta lembrar aqui o diagnóstico de Sílvio Romero sobre o assunto:

Na história do desenvolvimento espiritual do Brasil há uma lacuna a considerar: a falta de seriação na idéias, a ausência de uma genética. Por outros termos: um autor não procede de outro; um sistema não é conseqüência de outro que o precedeu. ${ }^{18}$

Quer dizer, Formação é o ponto de chegada de uma difícil continuidade de estudos de peso e alcance diferenciados. Somando os esforços de críticos de tendências diversas, Antonio Candido os aliou à sua própria perspectiva, construindo assim um arco histórico que impede que as conquistas passadas sejam desperdiçadas.

Por fim, analisando o último aspecto entre os que atrás foram mencionados - articulação entre literatura e as relações culturais notemos que esse é o traço mais forte de atualidade do método de Formação, aparecendo como vetor de unidade e amadurecimento da crítica literária no Brasil.

Como se sabe, durante toda sua atividade como crítico, Antonio Candido sempre voltou sua atenção para a análise da literatura como produto cultural de uma sociedade, isto é, como marcação simbólica e esteticamente transfigurada das relações sociais efetivas:

Entre as minhas preocupações, ligadas certamente à minha formação sociológica, está o problema da obra com o meio social e com a cultura. Se há uma orientação geral da minha atividade, tanto no campo da sociologia como no campo da literatura, eu diria que é a paixão do

${ }^{18}$ ROMERO, 1962, p. 57. 
concreto. Na literatura, o texto; na sociologia, o contato direto com os fatos sociais. ${ }^{19}$

E são justamente essas as preocupações que orientam uma das correntes teórico-críticas da atualidade: os Estudos Culturais. Bem comparadas, no entanto, as duas tendências apresentam nuanças que precisam ser discutidas.

Para começar, lembremos que a formação intelectual de Antonio Candido se deu nos anos de 1930 - período de grandes mudanças nos planos da cultura, da economia e da política - mediante inserção no meio arejado da Faculdade de Filosofia da USP e atuação crítica do grupo Clima. ${ }^{20}$ A base dessa formação possui duas faces: uma voltada para os problemas sociais do país, o que acabaria influenciando a atitude militante participativa de dos membros do grupo e outra voltada para a preocupação teórica que procurava ver a cultura como produto das relações sociais e, ao mesmo tempo, capaz de influir sobre elas e alterar-lhes o rumo. Ao lado de Ruy Coelho, Décio de Almeida Prado, Lorival Gomes Machado e Paulo Emílio Salles Gomes (o mais radical de todos), Antonio Candido procurou desde esse tempo conciliar essas duas faces com uma espécie de ambição iluminista que acreditava no desentrave cultural como meio para alcançar a democracia política e social. Ademais, o grupo de Clima era eclético e tinha interesses diversificados, voltando-se para a literatura, as artes plásticas, o teatro e o cinema ao mesmo tempo em que cultivava dentro ou fora da universidade interesse pela antropologia, sociologia, filosofia e história. As questões ideológicas de fundo tinham orientação socialista e comunista, acompanhando as tendências do mundo na época e respondendo às demandas do país que vivia sob a sombra do semifascismo de Vargas.

Ecletismo e ideologia são também as marcas dos Estudos Culturais, ${ }^{21}$ embora sejam de natureza diversa. No que diz respeito ao ecletismo, aqui a dimensão estética - tão cultivada nos anos 40 - perde um pouco sua força, mas, em compensação, a tendência à multidisciplinaridade se torna uma conquista estabilizada. Desse modo, como questão teórica de grande relevância, a multidisciplinaridade adquiriu contornos mais nítidos e precisos, sua existência se tornou uma necessidade que incentivava (e

\footnotetext{
${ }^{19}$ Entrevista de Antonio Candido a Luiz C. Jackson. In: JACKSON, 2002, p. 126.

${ }^{20}$ PONTES, 1998, p. 89-95.

${ }^{21}$ CEVASCO, 2003, p.60-78.
} 
ainda incentiva de fato) a qualidade da reflexão e ao mesmo tempo ajudou a depurar conteúdos variados de conhecimento. Assim, história, filosofia, artes visuais, sociologia, psicanálise etc. se constituíram como perspectivas críticas distintas que se iluminam reciprocamente, definindo melhor os contornos rarefeitos dessa coisa chamada cultura e aprofundando suas implicações, que são muitas. O aspecto ideológico também está presente entre os fundamentos dos Estudos Culturais e é bem forte. Nesse caso, a tendência socialista, baseada na compreensão da sociedade mediada por relações de classe, cede lugar a uma tendência mais preocupada com as relações entre micro-grupos, as chamadas minorias e, no lugar da preocupação com as causas das desigualdades entre nações orientadas pelas grandes corporações econômicas que se escondem atrás de políticas de Estado, a atenção se volta para os efeitos causados nos países periféricos, agora chamados pós-coloniais.

Com interesse voltado para uma comparação geral, percebe-se uma convergência entre os procedimentos e os ideais; comparando as datas vemos que as conquistas de Antonio Candido vieram antes e com intensidade, afinal vinham acompanhando as renovações nas ciências sociais no Brasil. Por outro lado, é forçoso dizer que, de um certo ponto de vista, embora utilizada nas universidades e citada em livros diversos de história e crítica literárias, Formação não contribuiu muito para uma reformulação mais duradoura na maneira de se estudar literatura com inclinação acentuada para sua relação com a sociedade e a cultura. Com exceção de alguns poucos outros críticos - em sua maioria ex-alunos e ex-orientados do professor que junto com ele formaram uma espécie de staff da crítica sociológica mais refinada - o método crítico de Antonio Candido não foi seguido ou desenvolvido em massa, embora gozasse da admiração de quase todos. A impressão que fica é que naquilo que Formação era mais inovadora, passou despercebida, justamente porque faltava aos interessados em literatura a mesma formação substanciosa do autor do livro no campo da teoria que ele praticava: o traspassamento formal entre sociedade, cultura e literatura. Hoje a situação mudou muito, principalmente por causa do aparecimento e da consolidação dos Estudos Culturais no Brasil, fato que começou a ocorrer a partir do início dos anos 90 e adquiriu caráter oficial em 1998 quando o tema "Literatura Comparada = Estudos Culturais?" foi escolhido para o Congresso Internacional da Associação Brasileira de Literatura Comparada, a ABRALIC.

Historicizando um pouco, os Estudos Culturais começaram a se consolidar a partir de um movimento da "nova esquerda" inglesa, com forte 
influência marxista, mas fora do domínio de correntes mais ortodoxas que obedeciam orientações soviéticas ou chinesas: as bases de construção dessa tendência foram o "Center for Contemporary Studies" da Universidade de Birmingham e, mais tarde, a "New Left Review", e reuniam nomes como Stuart Hall, Edward Thmpson, Eric Hobsbawn e Raymand Williams, todos ligados à esquerda do Partido Comunista inglês. A "nova esquerda" foi uma das maiores responsáveis - logo depois da Segunda Guerra - pela consolidação do chamado "marxismo ocidental", menos mecanicista na análise entre sociedade e modos de produção e mais afeito à análise das transformações ideológicas e culturais nas sociedades contemporâneas. A renovação que trouxe para o âmbito dos estudos da sociedade influenciou a historiografia, a filosofia, a sociologia, a crítica de arte e de literatura, pois sua preocupação central era estabelecer os vínculos mediadores entre sociedade e cultura. A partir da década de 1960, com o questionamento dos modelos ideológicos e políticos hegemônicos, esse viés crítico ganhou mais força e conquistou o mundo: agora, além da tarefa de análise da cultura, havia também a ambição de questionamento e transformação das assimetrias sócio-culturais que a realidade apresentava. A introdução dessa perspectiva crítica no Brasil obedeceu mais ou menos as mesmas orientações que a fizeram popular no mundo, especialmente nos países pós-coloniais - não há como negar, por exemplo, sua boa fama na América Latina. Assim, seguindo um padrão estabelecido há séculos - padrão esse tão bem analisado pelos autores citados nesse artigo e seus livros dedicados à análise da formação histórico-sócio-cultural brasileira - habituamo-nos a importar teorias seguindo a ordem e o ritmo das modas teóricas internacionais. Dessa maneira, uma das razões porque os Estudos Culturais gozam de grande prestígio no Brasil hoje, é fruto de nossa tradição quebrada, resultado daquela ausência de continuidade de que se queixava Sílvio Romero há mais de cem anos. ${ }^{22}$

\footnotetext{
${ }^{22}$ Trata-se da repetição no âmbito da cultura acadêmica do antigo modelo de substituição de importações, que atesta, segundo um crítico da cultura, "o esforço de atualização e desprovincianização em nossa universidade. Mas é fácil observar que só raramente a passagem de uma escola para outra corresponde, como seria de se esperar, ao esgotamento de um projeto; no geral ela se deve ao prestígio americano ou europeu da doutrina seguinte. Resulta a impressão - decepcionante - da mudança sem necessidade interna, e por isso mesmo sem proveito." SCHWARZ, 1989, p. 30.
} 
Voltando à comparação entre a contribuição de Antonio Candido e dos Estudos Culturais, existe uma aproximação na orientação e nas motivações que permanecem as mesmas, embora alteradas. Quer dizer, essas características emparelham idéias e procedimentos, mas não esgotam o problema. O principal, o que mais interessa analisar - questões de método - aparece como um nó difícil de desatar, pois ao mesmo tempo em que os assemelham e os fazem pertencerem a uma tendência, os afastam e ressalta o desnível entre ambos. O vetor que aproxima as duas orientações metodológicas é a possibilidade de realizar a crítica literária através da cultura e da sociedade e vice-versa. Mas isso nos deixa no plano das generalidades. O que especifica tais relações acaba por afastar as duas tendências e, neste caso, existem dois pontos que interessa destacar.

Em primeiro lugar devemos lembrar que a perspectiva crítica de Antonio Candido não é culturalista e sim materialista. Isso quer dizer que ao invés de simplesmente ver a literatura como algo que permite que se analise e se compreenda a sociedade, ela aparece como sua reprodução, algo que repete o padrão histórico, mas de modo diferenciado. Assim, a articulação entre literatura e sociedade se dá em um nível mais complexo (no nível da forma) e mais substanciado numa reflexão sobre o conjunto de relações especificadas historicamente. A história aqui não é uma abstração com contornos temporais, mas a objetivação de relações sociais mediadoras de condições econômicas, políticas e ideológicas. Portanto, a complexidade e a substância dessa reflexão estão lastreadas pela noção materialista de forma, conceito através do qual a análise permite compreender a ação e reação recíprocas entre texto e contexto. Voltarei a esse ponto logo adiante.

O segundo ponto diz respeito a uma certa hermenêutica textual: nos Estudos Culturais a literatura aparece - no mais das vezes - como prova a aferir os dados culturais mais variados (da condição pós-colonial à dificuldade de acesso ao conhecimento por parte dos pobres, das questões de gênero às de raça, passando por uma infinidade de temas mais ou menos conexos), na obra de Antonio Candido a literatura aparece como fatura - não como pressuposto nem como resultado - dos dados sócio-culturais. Basta lembrar aqui as poucas palavras que escreveu sobre seu método de trabalho no prefácio a um de seus livros (Antonio Candido, como se sabe, não é vezeiro de alardear metodologias e nem discutir à exaustão questões teóricas, preferindo divulgar seus resultados na forma de análise e interpretação de obras literárias). 
Os ensaios da primeira parte deste livro tentam analisar casos do que chamei "redução estrutural", isto é, processo por cujo intermédio a realidade do mundo e do ser se torna, na narrativa ficcional, componente de uma estrutura literária, permitindo que esta seja estudada em si mesma, como algo autônomo. O meu propósito é fazer uma crítica integradora, capaz de mostrar (não apenas enunciar teoricamente, como é hábito) de que maneira a narrativa se constitui a partir de materiais não literários, manipulados a fim de se tornarem aspectos de uma organização estética regida pelas suas próprias leis, não as da natureza, da sociedade ou do ser. ${ }^{23}$

Esse objetivo percorre todos os seus livros e se realiza em cada um deles, estando presente também em Formação, embora aqui apareça sob a forma de um paradoxo: ora o crítico atribui independência à literatura ("uma obra é uma realidade autônoma"), ${ }^{24}$ ora como algo constituído historicamente ("expressão da realidade"). ${ }^{25}$ Esse paradoxo, no entanto, não é propriamente daquele que ele observa e analisa e sim da realidade observada e analisada, ou seja, a força do método consiste em decantar a força do objeto que interpreta. É tarefa do ato crítico acompanhar esse movimento: "uma crítica equilibrada não pode aceitar falsas incompatibilidades, procurando, ao contrário, mostrar que são partes de uma explicação tanto quanto possível total." ${ }^{26}$ Em outra passagem vem a confirmação desse procedimento metodológico, agora aplicado ao exame da obra particular:

Por coerência, entende-se aqui a integração orgânica dos diferentes elementos e fatores (meio, vida idéias, temas, imagens, etc.), formando uma diretriz, um tom, um conjunto, cuja descoberta explica a obra como fórmula, obtida pela elaboração do escritor. É a adesão recíproca dos elementos e fatores dando lugar a uma unidade superior; mas não se confunde com a simplicidade, pois uma obra pode ser contraditória sem ser incoerente, se as suas condições forem superadas pela organização formal. ${ }^{27}$

\footnotetext{
${ }^{23}$ CANDIDO, 1993, p. 9.

${ }^{24}$ CANDIDO, 1981, p. 34.

${ }^{25}$ CANDIDO, 1981, p. 25.

${ }^{26}$ CANDIDO, 1981, p. 31.

${ }^{27}$ CANDIDO, 1981, p. 38.
} 
Note-se nas últimas linhas a importância estruturadora que o crítico atribui à forma e veremos que ela delimita as aproximações entre a perspectiva crítica desenvolvida por Candido e a desenvolvida pelos Estudos Culturais, quer dizer, as características acima apontadas aproximam uma tendência crítica da outra, mas a ênfase metodológica as difere e as especifica. Nos escritos de Antonio Candido não aparece o cotejamento texto-contexto, tão comumente encontrado em estudos com a mesma ambição de relacionar arte e sociedade, mas o enfoque efetivo dos elementos que, não sendo estéticos a princípio, tornam-se linguagem, isto é, são estruturados de tal modo que seus componentes internos tornam-se meios expressivos de manifestação coerente cujo efeito se conforma no belo literário. Trata-se aqui de uma questão formal, sendo que a forma possui nesse esquema duas atribuições: ela determina a organização interna de uma obra e ela especifica as linhas de configuração artística da realidade histórico-social. A esse respeito, o próprio crítico chama atenção para o fato de que "a forma, através da qual se manifesta o conteúdo, perfazendo com ele a expressão, é uma tentativa mais ou menos feliz e duradoura de equilíbrio entre os contrastes", isto é, capaz de captar e tornar estético, "um movimento amplo e constante entre o geral e o particular." 28 O andamento da análise se desenvolve assim porque parte do pressuposto de que a realidade histórico-social é - ela mesma - uma forma ${ }^{29}$ Dessa maneira, o lugar comum que prevê a superação da distância existente entre o interno e o externo - quando se fala em estudos sociais e históricos da literatura - conquista um patamar superior de análise e deixa para trás técnicas de análise menos penetrantes.

O resultado final realça a diferença atrás apontada: quem quer que leia Formação tem diante dos olhos os percalços histórico, social e cultural do país manifestados no campo da literatura, que assim ganha densidade e racionalidade reais. Não são as conclusões adquiridas no campo dos estudos históricos e culturais que explicam a "formação" da literatura no Brasil, mas o estudo de obras e as relações entre elas que dão forma à "formação" da literatura no país na perspectiva histórico-cultural. Em

${ }^{28}$ CANDIDO, 1981, p. 31.

29 Trata-se aqui de um dos fundamentos do materialismo dialético, pouco conhecido e usado nos estudos de historiografia literária, mas o qual Antonio Candido deu provas - mais de uma vez - de conhecer tão bem. A esse respeito ver ARANTES, 1992. 
síntese, Antonio Candido parte do exame dos textos literários, ele os estuda nos detalhes e interpreta as articulações entre eles perfazendo um arco cuja envergadura vai além do estético e explica a cultura e a sociedade como um todo. Assim, a literatura apresenta, em outra chave, os mesmos desencontros que a matriz objetiva martela: o livro revela impasses e viravoltas que se vive no país há séculos a partir de um esquema de interpretação reduzido a duas escolas literárias. É que elas representam a "redução estrutural" do processo formativo de nossa literatura.

Por todas as razões lembradas e analisadas aqui, a Formação da literatura brasileira continua, quase meio século depois, um livro de importância singular, pois, a par de analisar esteticamente um conjunto de obras e autores capitais do nosso acervo literário, os alça à condição de pensadores da constituição da sociedade e da cultura brasileiras e seus impasses. Tudo isso sem patriotada e com senso histórico que alinha o livro à altura dos que interpretaram o país.

\section{Referências Bibliográficas}

AGUILAR, Gonzalo. Anexo: Construir o passado: alguns problemas da história da literatura a partir do debate entre Antonio Candido e Haroldo de Campos. In: Poesia concreta no Brasil: as vanguardas na encruzilhada modernista. São Paulo: Edusp, 2005. p. 335-356.

ARANTES, Paulo Eduardo. Sentimento da dialética na experiência intelectual brasileira. São Paulo: Paz e Terra, 1992.

ASSIS, Machado de. Notícia da atual literatura brasileira - Instinto de nacionalidade. In: Obra completa. 9. ed. Rio de Janeiro: Nova Aguilar, 1994, v. 3. p. 801-809.

BAREL, Ana Beatriz Demarchi. Um romantismo a oeste: modelo francês, identidade nacional. São Paulo: Annablume, 2002.

BOSI, Alfredo. Um mito sacrificial: o indianismo de Alencar. In: Dialética da colonização. São Paulo: Companhia das Letras, 1992. p. 176-193.

CAMPOS, Haroldo de. O seqüestro do barroco na "Formação da literatura brasileira": o caso Gregório de Mattos. Salvador: Fundação Casa de Jorge Amado, 1989.

CANDIDO, Antonio. Formação da literatura brasileira: momentos decisivos. 6. ed. Belo Horizonte: Itatiaia, 1981. 
CANDIDO, Antonio. Prefácio. In: HOLANDA, Sérgio Buarque de. Raizes do Brasil. 14. ed. Rio de janeiro: José Olympio, 1981. p. XI-XXII.

CANDIDO, Antonio. O discurso e a cidade. São Paulo: Duas Cidades, 1993.

CEVASCO, Maria Elisa. Dez lições sobre estudos culturais. São Paulo: Boitempo, 2003.

COUTINHO, Afrânio. Conceito de literatura brasileira. Rio de Janeiro: Acadêmica, 1960.

COUTINHO, Afrânio. A tradução afortunada: o espírito de nacionalidade na crítica brasileira. Rio de Janeiro: José Olympio; São Paulo: Edusp, 1968.

GOMES Jr., Guilherme Simões. A controvérsia do Barroco no Brasil. In: Palavra peregrina: o barroco e o pensamento sobre artes e letras no Brasil. São Paulo: Edusp, 1998. p. 89-159.

HOLANDA, Sérgio Buarque de. Capítulos de literatura colonial. São Paulo: Brasiliense, 1991.

LIMA, Luiz Costa. Concepção de história literária na Formação. In: Pensando nos trópicos. Rio de Janeiro: Rocco, 1991. p. 149-166.

LOPES, Edward. Metamorfoses: a poesia de Cláudio Manuel da Costa. São Paulo: Unesp, 1995.

MOTTA, Leda Tenório. Sobre a crítica literária brasileira no último meio século. Rio de Janeiro: Imago, 2002.

PINTO, Maria Cecília de Moraes. Avida selvagem: paralelo entre Chateaubriand e Alencar. São Paulo Annablume, 1995.

PONTES, Heloísa. Destinos mistos: os críticos do grupo Clima em São Paulo. São Paulo: Companhia das Letras, 1998.

PRADO Jr., Caio. Formação do Brasil Contemporâneo. 21. ed. São Paulo: Brasiliense, 1989.

ROMERO, Ś́lvio. A filosofia no Brasil. In: Obra filosófica. 5. ed. Rio de Janeiro: José Olympio, 1962. p. 27-42.

SCHWARZ, Roberto. Nacional por subtração. In: Que horas são? São Paulo: Companhia das Letras, 1989. p. 29-48.

SERNA, Jorge Antonio Ruedas de la. Arcádia: tradição e mudança. São Paulo: Edusp, 1995. 


\section{Resumo}

O presente artigo traz uma análise do livro de Antonio Candido (Formação da literatura brasileira), acompanhando o seu desenvolvimento e destacando um de seus traços fundamentais de seu pensamento: o método crítico.

\section{Abstract}

The present study introduces an analyses of the Antonio Candido's book (Formação da literatura brasileira), following its movement and distinguishing some essential marks of the Candido's thought: the critical method. 